\title{
A difusão da tablatura para teclados e o exercício cortesão da arte da música no Renascimento
}

DELPHIM REZENDE PORTO 1

ECA/USP (delfim@usp.br)

\section{Introdução}

Xo contexto retórico, segundo FURLAN (2006, p. 17), Artes eram atividades ou disciplinas ou ocupações em que o conhecimento teórico estava vinculado às habilidades práticas - algo distinto das Scientiae que tratavam exclusivamente do conhecimento especulativo. Nesse sentido, especialmente no século XVI e XVII, a Música, por compor-se de elementos tanto de Ciência quanto de Arte particular, assume notadamente um múltiplo estatuto e desfruta de diferentes fins e interesses. Enquanto Ciência, portanto, relacionada às matemáticas e inserida entre as disciplinas do quadrivium compreende aquilo a que os antigos chamavam de Música Especulativa ou Teórica e, enquanto Arte particular, encerra basicamente a sua prática - tanto oficiosa quanto liberal. Embora aparentemente essa justaposição não nos revele, à primeira vista, a sua complexa natureza contraditória ou complementar, ela é, sem dúvidas, além da característica mais significativa do período em questão, o apogeu de um desenvolvimento iniciado no século décimo primeiro por Guido Aretino - segundo a tradição narrada por EXÍMENO (1774) quando da restauração [ou renascimento] da Música depois da invasão dos Bárbaros na Europa.

\section{A música no Renascimento e seus fins}

Assunto nos principais escritos humanistas do século XVI, a música é objeto de discussão e interesse de músicos e

${ }^{1} 0$ autor recebe bolsa de doutorado (processo $\left.n^{\circ} 2014 / 26766-2\right)$ da Fundação de Amparo à Pesquisa do Estado de São Paulo (FAPESP). As opiniões, hipóteses e conclusões ou recomendações expressas nesse material são de responsabilidade do autor e não necessariamente refletem a visão da FAPESP. 
cortesãos (ou gentis-homens). Diversos autores, como Alessandro Piccolomini (1508-1579) e Baltassare Castiglione (1478-1529), registram em suas obras importantes considerações sobre a natureza e os diversos fins que a música pode assumir de acordo com seus artífices e circunstâncias. Os comentários e emulações que elaboram, sobretudo, a partir dos tópicos das auctoritates gregas e latinas - difundidas em traduções e comentários impressos naquele século ${ }^{2}-$ de filósofos como Aristóteles e Boécio, para além da composição retórica típica da escritura do período, constituem de certa forma o próprio pensamento e funcionamento daquela sociedade, no qual a música é considerada ora ornamento de bons costumes ora assunto das matemáticas (ou ambos).

Alessandro PICCOLOMINI (1559) ao redigir um programa de educação para um "homem nascido nobre e em cidade livre" (Della institutione di tutta la vita dell' huomo nato nobile, $e$ in città libera), reserva a música - capítulo X, XI e XIV e a sua aprendizagem a específicos momentos do desenvolvimento do infante e do jovem. Ao considerar a divisão clássica da música enquanto arte e ciência, o autor argumenta que há três fins da música para o nobre: fazer perfeito o ouvido, ser um ócio honesto e mover os ânimos através dos efeitos e afetos em música. A educação do ouvido do gentilhuomo, segundo este autor, serve para que aquele cortesão possa compreender as proporções musicais e desfrutá-las em sua beleza mais intelectual, verdadeira, para além das sensações vis - que corrompem o homem - presentes na música vulgar. Enquanto "ornamento dos costumes", aprender a cantar ou a tocar um instrumento, está intimamente ligado ao exercício que os homens devem buscar nas horas de

\footnotetext{
${ }^{2}$ Segundo Yebra no seu prefácio à tradução da Poética (ARISTÓTELES, 1974, p.18), ao longo do século XVI, em Veneza se viu surgir diversas edições impressas dessa obra do estagirita, por exemplo. Kristeller (1990, p.17), analogamente, discorre sobre a studia humanitatis difundida a partir da Itália que considerava prioritário o estudo sistemático da antiguidade clássica, desde a filosofia, história, retórica e outras artes particulares, como a música, e a difusão impressa daqueles manuscritos, em língua vulgar.
} 
lazer, para, através de uma prática também intelectual, recrearem-se. Entretanto, apenas uma parte do dia poderia ser destinada a isso para que não se tornasse um ofício. No âmbito das matemáticas, mais proveito teria o nobre se pudesse também estudar a música especulativa, matemática (1559, cap. XIV): "E tudo isso diz até aqui entendendo da música segundo aquele uso, porém sobre a teórica, dela argumentaremos quando falarmos das matemáticas, por ser a música subalternada à aritmética (tradução nossa).” ${ }^{3}$ CASTIGLIONE (1528) no diálogo do Il Corteggiano difunde as mesmas ideias quanto ao ócio honesto, acrescentando que o cortesão, ao tocar um instrumento, deveria escolher aquele que durante o exercício não lhe deformasse nem o rosto nem o obrigasse a uma postura que não fosse conveniente a sua natureza nobre, como admite PÉCORA (1997, p. xii):

A preferência deixa manifesto o gosto cortesão pela preponderância do texto poético (que podia ser Petrarca, Sannazaro ou Galeota) sobre a música pura, o que basta para diferenciá-los decisivamente da tendência franco-flamenga de recusar quaisquer elementos externos à determinação polifônica da Ars Perfecta. [...] 0 prazer intelectual da audição nítida dos poemas, recortado pelos toques da viola, casa-se admiravelmente com a ideia de que afinal gentis-homens são diletantes musicais. Vale dizer, se devem tocar algum instrumento e conhecer música, não o devem fazer de modo a ultrapassar o limite restrito aos profissionais, em que a prática sistemática dos instrumentos pode provocar deformações profissionais no rosto, no corpo, no porte, ou, enfim, reduzir o alcance universal da formação ao específico particular.

Tais argumentos podem ser lidos como uma emenda retórica ao oitavo livro da Política de Aristóteles, no qual, particularmente, o autor trata da música e da educação. A questão fundamental a que o filósofo grego se refere é a do exercício da música como ócio honesto e virtuoso pelo homem

\footnotetext{
${ }^{3}$ E tutto questo ho detto fin qui intendendo della musica secondo l'uso di quella, però che quanto alla teorica ne ragionaremo quando delle matematiche parlaremo, per esser la musica all'aritmetica subalterna.
} 
livre, uma vez que essa arte não se constitui como uma necessidade, portanto, não indispensável: "resta, pois, que ela seja útil para as horas de descanso, o que a faz ser admitida como parte da educação. Compreendeu-se neste nome aquilo que se considera uma distração dos homens livres" (ARISTÓTELES, 2009, p. 270). A este fim, segue-se uma série de justificativas encontradas como lugar comum dos escritores italianos do cinquecento que frequentam a música. Para tanto, apontamos didaticamente seis razões que consideramos recorrentes.

A primeira delas (cap.II) declara que há uma dupla tendência em algumas artes e ciências tanto de liberalidade quanto servilismo; porém, não quando cultivadas até o ponto adequado e para um fim liberal - uma vez que não é bom que se participe do prazer e do estudo apenas pelo talento alheio (cap. IV).

A segunda (cap. V) declara que a música é, ao mesmo tempo, uma ciência, um prazer e um passatempo. A terceira declara que a juventude é precisamente a idade própria ao estudo dessa arte. A quarta (cap. VI) adverte que, para bem julgar uma arte, é necessário a ela estar afeito, pelo menos o suficiente para "sentir prazer nos cantos e ritmos que têm uma beleza real e não somente na música comum e vulgar que agrada até mesmo a certos animais e à multidão dos escravos e das crianças" (ARISTÓTELES, 2009, p.278). A quinta (cap. VII) situa as deformações e movimentos que o corpo é obrigado a fazer pelo jogo de alguns instrumentos como uma coisa vil e grosseira. A sexta e última está no capítulo sétimo e se refere à natureza do espectador (ARISTÓTELES, 2009, p. 281):

No entanto, havendo duas espécies de espectadores, uns homens livres e bem educados, outros grosseiros, artesãos, mercenários e semelhantes, é preciso também conceder a esses últimos diversões e representações próprias a distraílos. Do mesmo modo que as suas almas são desviadas da via natural, assim as suas harmonias se afastam das regras da arte; os seus cantos têm uma rusticidade forçada e uma cor falsa. Cada qual só encontra prazer naquilo que se adapta à sua natureza. É preciso, pois conceder aos que exibem a sua arte a tais ouvintes, a liberdade de fazer uso desses gêneros 
de música. Mas na educação, como já foi dito, só se devem servir de cantos morais e harmonias convenientes.

A música, enquanto conhecimento especulativo, é referida primeiramente como "ciência subalternada" argumento sediado no corpo filosófico de Aristóteles e descrito, especialmente, por São Tomás - seu comentador latino. Tal razão possibilita que a música, a ótica e a astronomia -scientiae mediae - demonstrem suas conclusões a partir de ciências principais - nomeadamente, a Aritmética e a Geometria: ciências subalternantes. Assim como a perspectiva subalternase à Geometria, a música, como demonstra Gioseffo ZARLINO (1517-1590) nas "Instituições Harmônicas" (1558, fl.30), toma da Aritmética os 'números [sonoros]' e da Geometria as "quantidades mensuráveis para construir os instrumentos", por exemplo.

Ainda: essa relação, científico-filosófica, da Matemática 234 com a Música, é completada por Avicena - comentador árabe do corpus aristotélico - e citada por G. ZARLINO, na compreensão de que "a música possui seus princípios tanto na ciência natural quanto naquela dos números" (1558, fl. 31). A emenda exposta aqui pelo discípulo de Adriano Willaert prossegue dizendo que "assim como, nas coisas naturais, potencialmente, nada é perfeito senão quando posto em prática, assim a música não pode ser perfeita senão quando, através de meios naturais ou de instrumentos artificiais, se faz ouvir". Nem a voz sozinha, nem o número sozinho, podem, para o tratadista - em referência à ciência natural e ciência matemática, por ele considerada respectivamente - bastar à compreensão do que venha a ser a música: da Natural, o músico empresta o som consonante - os sons artificiais e as vozes - e da Matemática, a forma, a proporção - os intervalos musicais, o temperamento, por exemplo.

Remissivo ao entendimento de Severino Boécio, a música pode ainda, no âmbito da ciência especulativa, ser entendida como harmonia universal. Tal premissa é tópico comum neste período e aparece de maneira unívoca quando tratam sobre a música teórica, como fazem Ludovici Folliani (1529), G. Maria Artusi (1585), Antonio Fernandez (1626) e 
outros. O próprio ZARLINO (1558, p. 10) alerta que há uma profusão de significados que a palavra 'música' assume. 'Música' ou 'harmonia' compreendem não apenas o som de interesse do músico, mas também o movimento dos corpos celestes e a harmonia medicinal dos humores do corpo do homem.

\section{A edição de música no século XVI para amadores e profissionais}

O exercício da música, especialmente no Renascimento, compreende essencialmente duas práticas: o ócio do cortesão liberal e o ofício do artífice profissional. Embora o fim da arte para cada um desses seja próprio e distinto, ambos demonstram interesse na realização musical revestida das preceptivas referidas acima - tanto especulativas quanto humanistas - e as edições musicais do período refletem essa dupla característica em sua escritura. Autores como Gioseffo ZARLINO (1558, fl. 9, tradução nossa) afirmam que o conhecimento apenas da música é insuficiente, seja para os diletantes quanto para os especialistas:

Não deve o homem apenas aprender a arte da música e abster-se das outras ciências, abandonando o seu fim - o que seria uma grande estupidez. Deve, contudo, aprendê-la segundo o fim para o qual foi ordenada, e não deve gastar tempo apenas com ela mas, acompanhá-la com o estudo da especulativa; uma vez que, ajudado por aquela, possa adquirir maior conhecimento das coisas, que ao uso da música, são intrínsecos, e mediante este uso possa executar praticamente aquilo que longamente investigou; Assim, deste modo, se torna útil a toda ciência e a toda arte, como já várias vezes vimos. ${ }^{4}$

\footnotetext{
${ }^{4}$ Non debbe adunque l' huomo solamente imparar l' arte della Musica, et ritrarsi dall' altre scienze, abbandonando il suo fine; che sarebbe gran pazzia: ma debbe impararla a quel fine, al quale è stata ordinata; Ne debbe spendere il tempo solamente in essa: ma debbe accompagnarla con lo studio della speculatiua; accioche da quella aiutato, possa venire in maggior cognitione delle cose, che all' vso di essa appartengono; et mediante quest' vso possa ridurre in atto
} 
Enquanto escritor de livros para o gentilhuomo, o valent'huomo - músico profissional referido por Girolamo DIRUTA no Il Transilvano (1593) - deve atuar como um tipo retórico de cortesão que idealmente domina as tópicas humanistas e as emprega no plano inartístico dos tratados. De fato, considerável parcela da produção musical renascentista atende decorosamente, antes do argumento puramente musical, uma demanda diletante de leitores não oficiosos - que para serem perfeitos gentis-homens, também devem conhecer música. A evidente semelhança dos adjetivos atribuídos a ambos os artífices é decerto indicativo do trânsito literário entre os mesmos e, possivelmente, a condição para a impressão e publicação de tais materiais naquele contexto.

No ano de 1600, G. B. ARTUSI, publica em Veneza um diálogo sobre as "Imperfeições da música moderna" (Delle 236 Imperfettioni della moderna musica) no qual Luca, um nobre estrangeiro e Vario, um aretino a serviço do cardeal Arrigoni ao qual é dedicada a obra - discutem artificiosamente as vantagens da antiga música grega, seus efeitos e teorias, em relação àquela contemporânea. Além de exaltarem os maravilhosos efeitos que aquela música imprimia sobre a audiência em comparação aos resultados obtidos por aquela contemporânea e elucidarem alguns princípios da música especulativa, ambas as personagens trazem luz a alguns pontos típicos da curiosidade diletante acerca da arte da música. 0 diálogo, forma da moda, estabelece um enredo aristocrático ao cenário, ao debate e ao próprio assunto - que acaba sendo pretexto para questões típicas de um amador, como a do efeito que faz colocar as cordas de um alaúde numa cítara para constatar se o mesmo fica com o som do outro instrumento (f.7) ou a de bem organizar um concerto: a eleição das peças, a distância e quantidade dos músicos e cantores necessárias para cada tipo de ambiente acústico, etc.

quello, che per lungo studio speculando hà inuestigato: imperoche accompagnata in tal modo porta vtile ad ogni scienza, et ad ogni arte, come altre volte habbiamo veduto. 
É neste diálogo que aparece o índice mais interessante sobre o duplo endereçamento das edições musicais renascentistas: a publicação de música em tablatura - e não em partitura. Sob a referida forma, tanto os profissionais da música quanto os cortesãos que não possuem treino suficiente para deitar ao teclado uma partitura polifônica poderiam executar uma peça musical. No fólio décimo temos, em nossa tradução:

A tablatura serve tanto aos Músicos quanto aos ignorantes de música: [...] para dispor, sob regras universais, o modo de fazer ouvir todas composições - quaisquer que sejam neste instrumento - como se pode ver que fizeram ao publicar tantas e variadas tablaturas, que servem, tanto aos inteligentes quanto aos ignorantes da Música - e nem seria possível fazê-lo de outro modo. ${ }^{5}$

Juan BERMUDO (1555, fl. 83), expoente ibérico do período, autor do tratado Declaración de instrumentos musicales, semelhantemente, aponta que é de muito proveito aos principiantes, sejam eles tocadores de vihuela ou monachordio, que seus mestres lhes ensinem esta arte de entabular, pois mesmo sem saber gamautare, isto é, sem conhecimento formal de música, através das cifras, poderiam tocar um moteto, por exemplo. ${ }^{6}$ Além disso, lembra o autor

\footnotetext{
${ }^{5}$ Intabolatura serue à Musici, \& à ignoranti di Musica[...]per ridure sotto regole universali, il modo di far sentire le Cõpositioni tutte, siano quali si vogliano in questo Instromento, come si uede, che hanno fatto con il dare nel publico tante, e tante uariate Intabolature, che seruono à ogni intelligente, \& ignorante della Musica, nè era possibile poter fare altrimenti.

${ }^{6}$ Este arte de cifrar a tres cosas sirve. La primera, para que si algun buen tañedor quiere tañer vn motete de improuiso (como lo hazen los buenos tañedores de vihuela) cifrando lo primero: sin falta lo puede tañer. No sera pequena alabança poner cãto de organo e nel monachordio de improviso: aunque sea por cifrar. La segunda seruira, para que si alguno quisiere tener mucho canto de organo em poco papel: lo tenga puesto en cifras. Quatro vezes mas ocupa el canto de organo puntado: que cifrado. Aprovechan mas las cifra: para los principiantes. Si vn maestro que enseña a tañer, tiene discípulos, que no saben cãtar: por cifras les puede em señar. Digo, que como ay
} 
que, um compositor, ao publicar suas obras sob a forma de tablatura, economiza quatro vezes menos papel do que se as editar em partitura.

Oportunamente pode-se dizer que a tablatura é um artifício típico do século XVI para dispor facilmente uma estrutura polifônica de modelo vocal sobre um instrumento de teclados, tanto a partir de uma partitura quanto de livros-parte. As mais famosas tablaturas são aquelas realizadas para instrumentos de teclado - órgão, monocórdio, espineta - e para viola da mano, alaúde, vihuela, guitarra. 0 princípio técnico da arte de entabular consiste, basicamente, em atribuir a cifras, números ou letras, certa equivalência às notas e ritmos de uma melodia ou de várias - encerradas em polifonia - tendo em vista as cordas ou as teclas do instrumento em questão ou ainda as mãos e os dedos do tocador. Esse tipo de notação musical difere, sobremaneira, daquela da partitura vocal porque ao invés de seus símbolos significarem a nota e seu ritmo tipicamente, representam os dedos do executante ou a corda ou nota que este deve tocar. Mesmo com muito pouco conhecimento de música um diletante por meio dessas cifras pode teoricamente tocar qualquer peça.

A profusão desse tipo de escrita no século XVI, especialmente, denota o interesse ou a demanda que aqueles compositores tinham em relação ao exercício da profissão, tendo que produzir um material que servia primeiramente aos que não eram peritos, ou seja, a nobreza que patrocina e, por ornamento dos costumes, também toca. Na tablatura ibérica para teclados, por exemplo, segundo a preceptiva registrada por BERMUDO (1555, fl. 62), a tablatura indica através de números - 1 a 42 - as notas do teclado que devem ser tocadas. Essa numeração compreende as teclas brancas e pretas do monochordio e, por meio de quatro linhas que representam as quatro vozes da polifonia - cantus, altus, tenor, bassus entabula uma peça polifônica para um tañedor curioso, como

tañedores de vihuela (sin saber el gamautare) por solas cifras: assi los puede auer enel monachordio, si les dan las cifras. 
vemos abaixo. Na primeira figura, temos os números na parte superior, indicando a tecla correspondente, e, na segunda, a tablatura propriamente. Notemos que o teclado em referência possui a primeira oitava curta, como demonstra a numeração 1-4-2-5-3 - Dó, Fá, Ré, Sol, Mi, respectivamente.

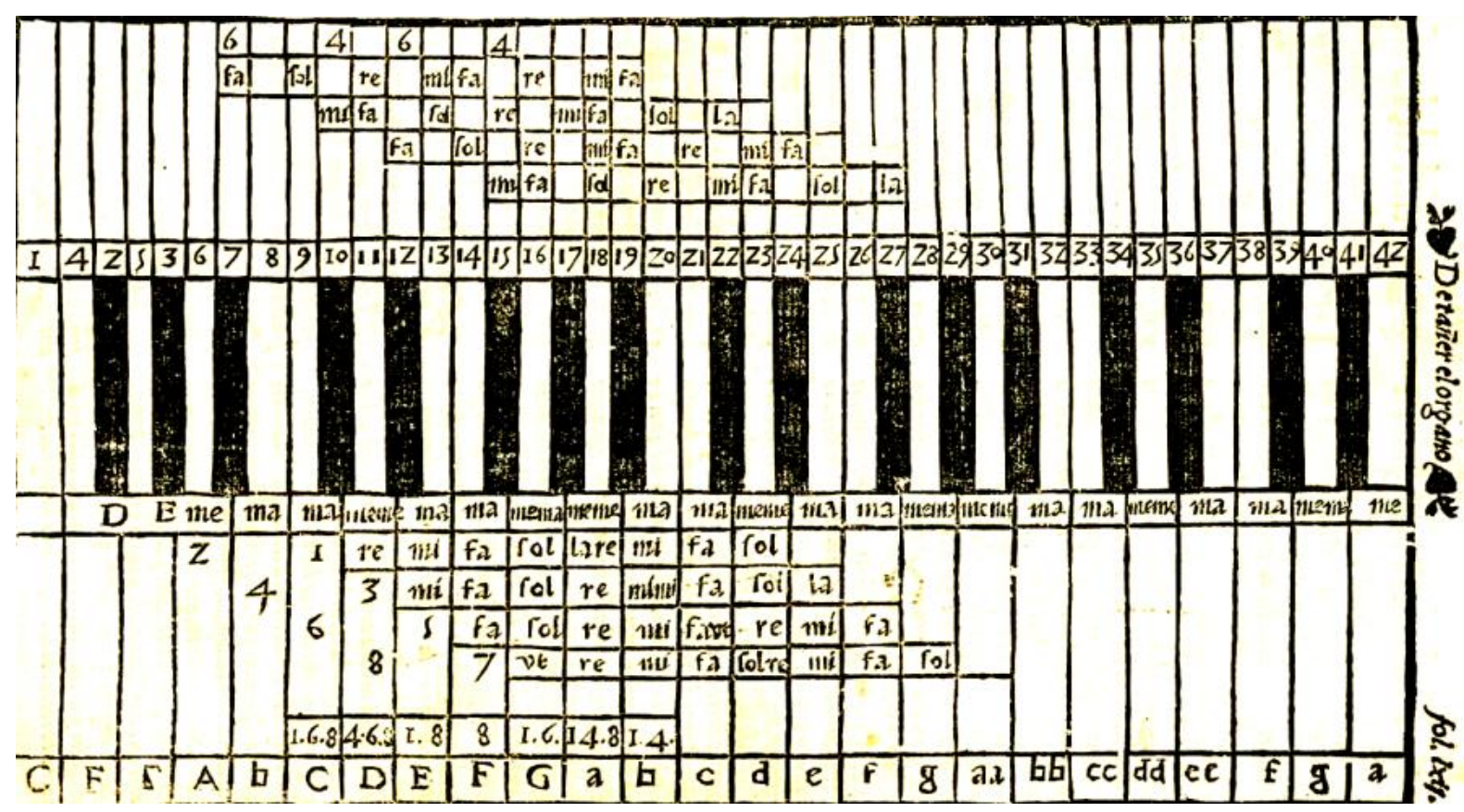

Figura1: Bermudo (1555, fl. 62) 


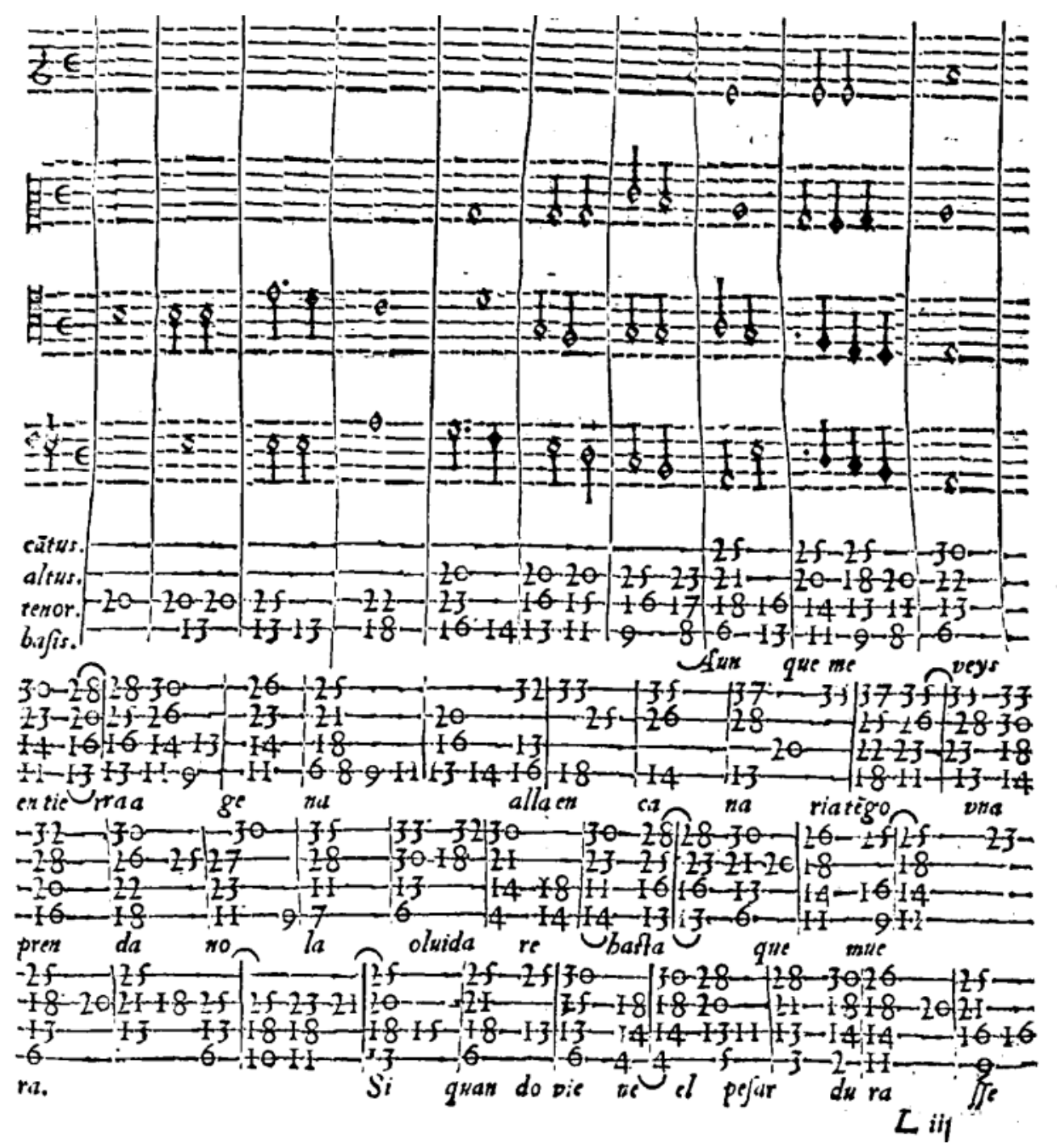

Figura 2: Bermudo (1555, fl. 83)

\section{A tablatura italiana e a gênese da escritura a duas pautas para teclados}

Segundo TAMMINGA (2010), a notação musical em tablatura encerrava principalmente a prática possível aos diletantes que não liam partitura - já que na tablatura a música estava resolvida com as diminuições e, muitas vezes, já indicavam as alterações da musica ficta - mas não só. A tablatura difundida a partir da Itália, muito embora pudesse ser essencialmente uma ferramenta de essência diletante, no contexto tecladístico daquele país, não servia apenas àqueles curiosos, dada a sua configuração muito semelhante à partitura 
vocal, constitui, verdadeiramente, a prática comum e necessária para se tocar, ao teclado, aquelas composições publicadas em partes separadas.

Se os Ricercari no séc. XVI eram publicados em livros-parte, o organista fazia a tablatura para teclado que comportava a exata divisão das partes entre as duas mãos. No ato executivo o organista acrescentava alterações segundo a praxe da música ficta e improvisava diminuições, sobretudo nas cadências entre as seções. É claro indício desta prática o modo como são entabuladas as cadências: três vozes são destinadas à mão esquerda, de modo que a direita fique livre para as diminuições. (TAMMINGA, 2010, p. iii, tradução nossa). ${ }^{7}$

A semelhança da tablatura italiana com aquela ibérica pode ser considerada apenas conceitual, uma vez que, tal como a última, também registra por extenso aquilo que normalmente seria improvisado e, ademais, como registro da execução, utiliza a divisão das mãos como critério para a disposição da polifonia - e só. Uma vez que é impossível, ou muito próximo disso, a leitura dos diversos livros-partes ao mesmo tempo, dada a disposição dos mesmos enquanto paginação, battuta e, também pela ausência do ensino dessa prática nos tratados oposta ao detalhado ensino da arte de entabular presente, por exemplo, no tratado de Diruta, fazia parte do aprendizado musical do tecladista a fatura deste artifício.

A música instrumental para teclados desse contexto poderia ser publicada tanto em livros separados das vozes que compunham a obra ou em spartitura - mais típica. Certamente o organista profissional sabia ler uma partitura de quatro pentagramas ao teclado, como indicam as diversas publicações

\footnotetext{
${ }^{7}$ Se i Ricercari nel sec. XVI erano pubblicati in libri-parte, l'organista faceva l'intavolatura per tastiera che comportava l'esata divisione delle parti tra le mani. Nell'atto esecutivo l'organista aggiungeva alterazioni, secondo la prassi della musica ficta, e improvvisava diminuzioni sopratutto nelle cadenze tra le sezioni. E' chiaro indizio di questa prassi il modo in cui sono intavolate le cadenze: tre voci sono destinate alla mano sinistra, in modo che la destra sia libera per le diminuzioni.
} 
sob esta forma neste período e também o interessante prefácio que Frescobaldi escreve para a edição da obra Fiori Musicali. Tendo publicado considerável parte das suas composições para teclado em intavolatura (tablatura), esta obra, que é dedicada aos organistas profissionais, foi impressa em partitura e é especial índice para o nosso argumento, pois, diz explicitamente que a leitura em partitura é o que separa os verdadeiros músicos daqueles diletantes, paragão das ações virtuosa daquelas dos ignorantes, nas palavras do compositor. Do exórdio de Fiori Musicali de Girolamo FRESCOBALDI, 1635, Veneza, sempre em nossa tradução:

Ao leitor

Tendo sempre sido disposto a favorecer com as minhas obras os estudiosos desta profissão - pelo talento que Deus me concedeu -, sempre demonstrei ao mundo com as minhas edições em Tablatura e em Partitura todo tipo de 'capricci' e 'invenções' o meu desejoso afeto para que todos, vendo e estudando as minhas obras, ficassem contentes e satisfeitos. Deste meu livro direi somente que o meu principal propósito é o de beneficiar os Organistas. [...] Estimo ser de muita importância aos músicos a leitura em Partitura - e a recomendo não somente a quem deseja executar esta obra, mas, porque é necessário, uma vez que tal matéria, quase paragão, distingue e faz conhecer o verdadeiro ouro das ações virtuosas, das dos ignorantes. ${ }^{8}$

\footnotetext{
${ }^{8}$ Al Lettore: Essendo stato sempre desideroso (per quel talento che mi è da Dio Conceduto) di giouare con le mie fatiche alli studiosi di detta professione, sempre ho dimostrato al mondo con le mie Stampe d'intauolatura, \& in partitura di ogni sorte capricci e d'inuentioni dar segno del mio dessideroso affetto, accio che ogniuno vedendo, e studiando le mie opre ne restasse contento, \& approfittato. Con questo mio libro dirò solo che il mio principal fine è di giouare alli Organisti [...], stimo di molta importanza à sonatori, il praticare le partiture perché non solo stimo, à chi ha desiderio affatticarsi in tal compositione ma necessario Essendo che tal materia quasi paragone distingue e fa conoscere il vero oro delle virtuose attioni dal Ignoranti
} 

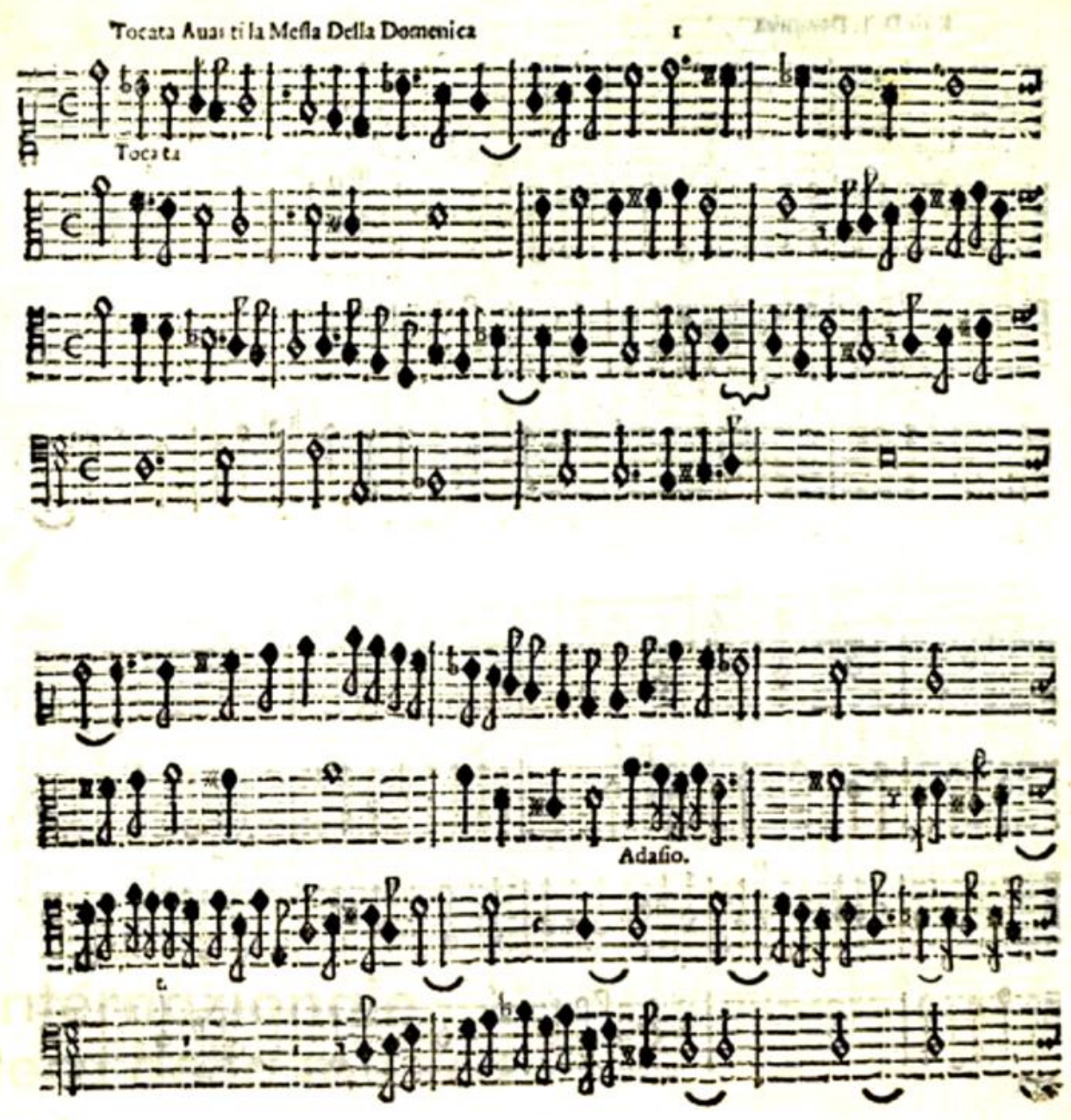

Figura 3: Frescolbaldi (1635, fl. A3)

Diruta no livro I da segunda parte do Transilvano descreve a problemática da arte de entabular necessária a todo organista que deseja tocar corretamente uma partitura a duas, três, quatro ou mais vozes. 0 primeiro passo é compreender dois conjuntos de linhas para comportar as vozes que serão tocadas pela mão direita - 5 linhas - e pela esquerda - 8 linhas. A quantidade de linhas não é objeto de explicação por parte do autor, mas nos parece coerente essa quantidade maior de linhas no conjunto referente à mão esquerda justamente pela prática de se tocar, nas cadências, três vozes com a mão esquerda e as diminuições na direita.

Sendo a tablatura o registro da prática daquela música, alguns indícios da sua performance são explicitados pelo nosso autor, como por exemplo, a maneira de tocar os uníssonos 
entre duas vozes diferentes, salientando que o organista deve indicar a nota tanto de uma voz quanto da outra, para que se possa escutar bem o caminho que a fuga trilha na composição, como se pode ver no excerto de uma partitura a três vozes (fig.4).

Embora o autor dê relevância ao desenho polifônico que as vozes perfazem enquanto resultado sonoro, visualmente não há indicação desse cruzamento - como se faz hodiernamente através da orientação das hastes das notas. No entanto, para a indicação temática do soggetto artificiosamente imitado, Diruta considera a colocação estratégica de pausas antes da nota que começa a figuração, portanto, para indicar a entrada de uma certa parte na polifonia. 0 autor ainda recomenda que não se coloquem pausas para indicar a ausência de uma voz em algum compasso para que aquela pausa longa não seja confundida com uma nota.

No exemplo, as três primeiras linhas são da partitura a três vozes e os dois últimos conjuntos de linhas, a tablatura para teclado. As flechas indicam o caminho do soggetto assegurado pela repetição da nota em uníssono e os círculos compreendem o mesmo uníssono, mas em outra voz.

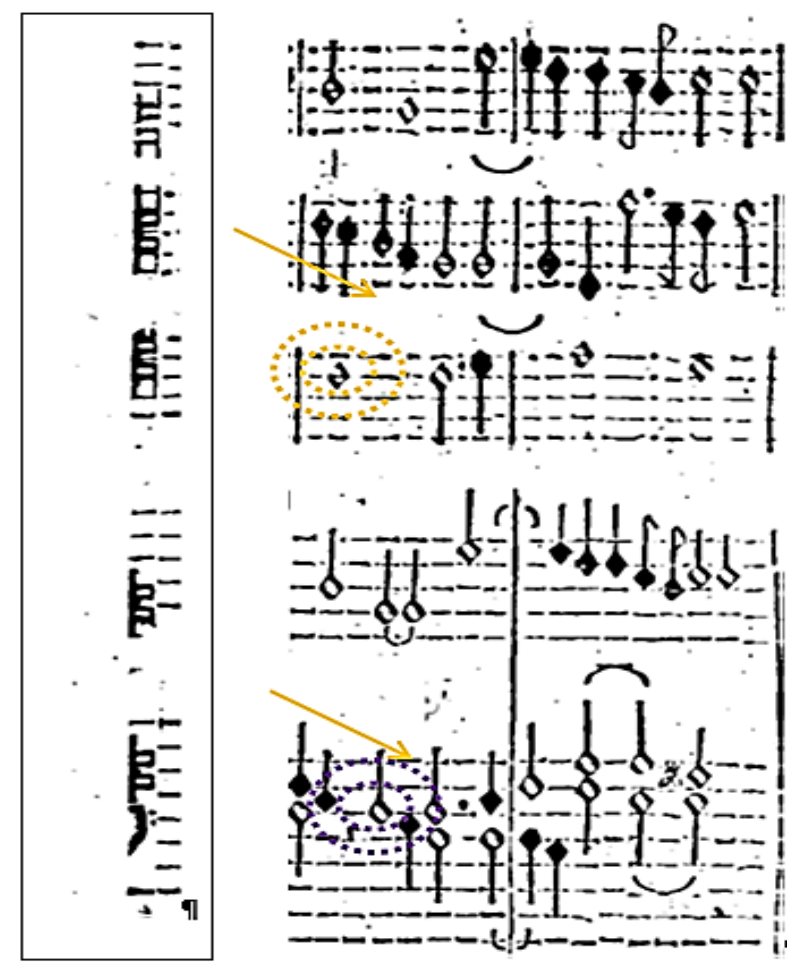


Além da divisão das vozes que compõem a obra entre as duas mãos do organista, a tablatura reduz para duas "pautas" as várias linhas das vozes, simplificando extraordinariamente a leitura para o instrumentista, uma vez que neste período são comuns obras compostas a mais de quatro vozes. A tablatura, segundo Diruta, pode ser de dois tipos: simples e diminuída. A primeira é a que vimos no exemplo acima, ou seja, uma redução para o teclado das várias vozes sem quaisquer acréscimos. A diminuída ${ }^{9}$, por outro lado, acrescenta à tablatura diversos tipos de ornamentos, não só cadenciais, mas, também, intrínsecos a própria constituição do soggetto temático. 0 tecladista deve, então, escolher o tipo de ornamentação adequada ao seu propósito e elaborar a diminuição dos soggetti imitados na composição, sem, contudo, deturpá-lo com excessos. Para este fim, Diruta elenca alguns tipos de diminuição e as aplica sobre as vozes da partitura, como se pode ver no exemplo abaixo (fig.5). As letras M, G e T, presentes no exemplo, se referem ao tipo de diminuição que o autor escolhe e entabula: minuta, groppi e tremolo, respectivamente.

\footnotetext{
${ }^{9} \mathrm{O}$ termo diminuição relativo à ornamentação quinhentista não deve ser confundido com o homônimo empregado no contexto do contraponto oitocentista.
} 
18. LIBROPRIMO:

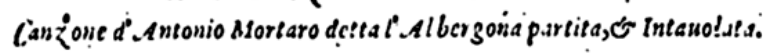

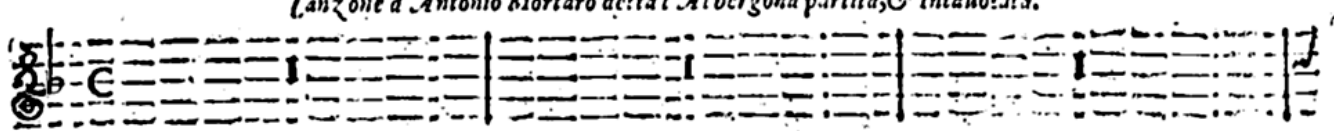

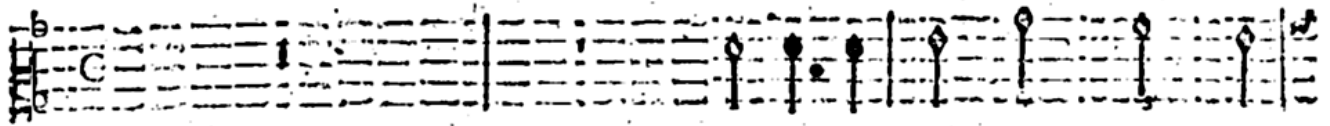

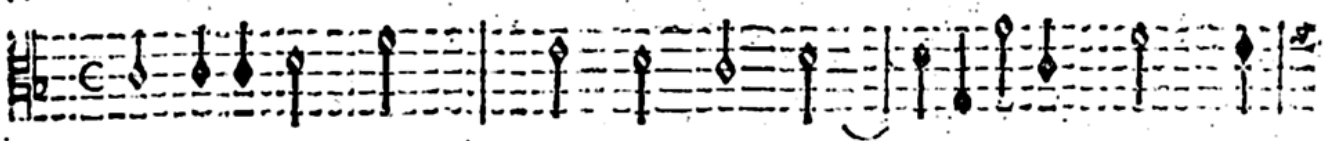

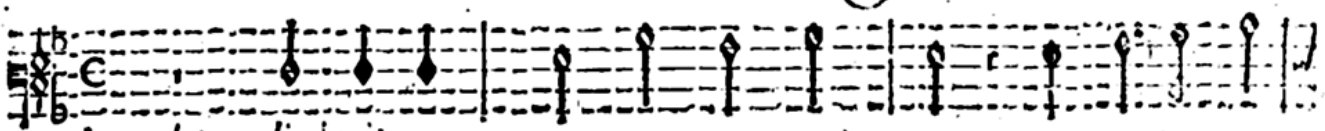

Intsuolatura diminuita.

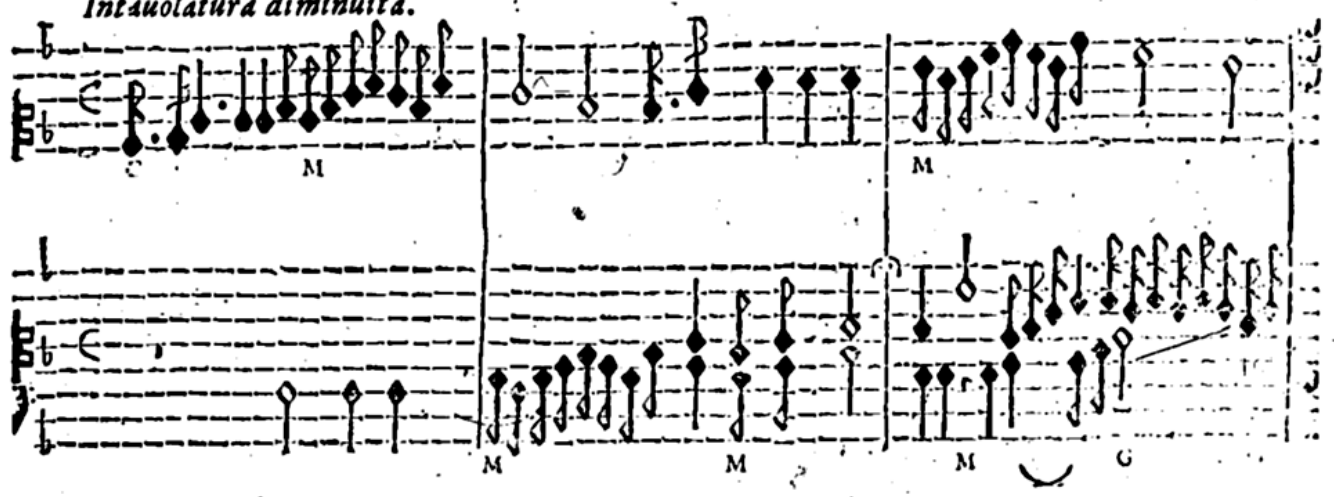

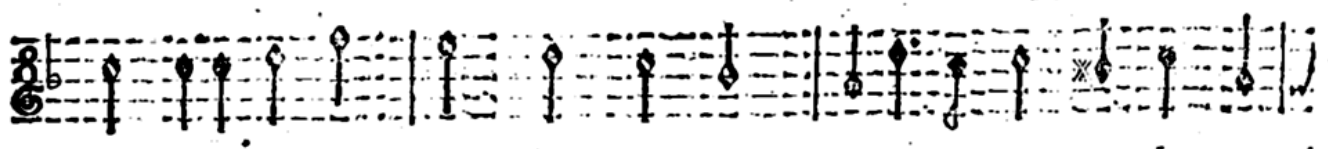

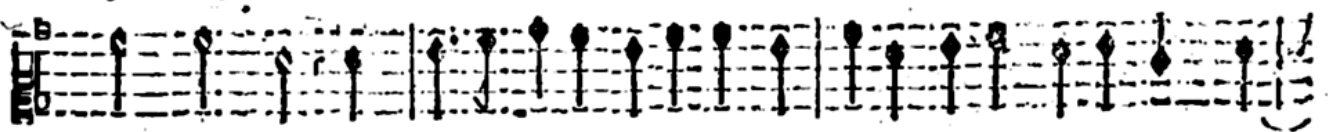
U1:

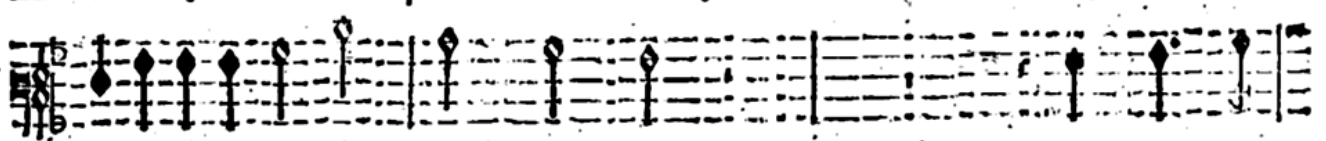

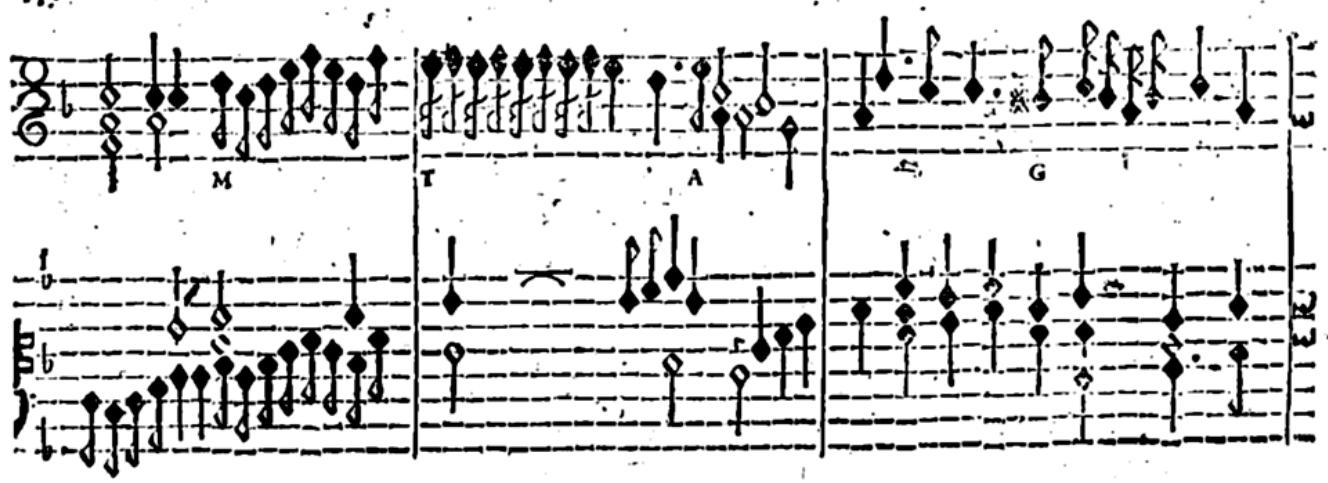

Figura 5: Canzona de Antonio Mortaro, entabulada e diminuída por G. Diruta, p.209. 


\section{Considerações finais}

O desenvolvimento da escrita musical para teclados sob a forma de tablatura, como vimos, tem suas raízes no histórico exercício cortesão da arte da música. Uma vez que dos profissionais, especialmente dos organistas, era esperada a leitura de uma partitura completa (modernamente conhecida como "grade"), é importante contextualizar o artifício da exposição de notas e ritmos reduzidas às mãos, em duas pautas - uma destinada à realização da mão direita e a seguinte, da esquerda - dentro de uma perspectiva essencialmente não oficiosa da música.

Como um registro já elaborado e ornamentado da matéria composicional, a tablatura dispõe de modo completo, por extenso, a realização que um artífice profissional daquela época faria de uma partitura ordinária indicando que as publicações e edições de música no Renascimento, especialmente, atendiam a demanda de um público que não a realizaria ou ornamentaria per se, bem como de aprendizes deste ofício. Além do aparato retórico que dá forma aos tratados e partituras publicadas no período, a prática editorial da tablatura, é, sem dúvidas, também índice do duplo fim dos livros de música - profissional e amador - e demonstra a profícua inter-relação, ainda pouco visitada, de ambos os tecladistas.

É interessante compreender igualmente a conversão de uma partitura à tablatura como o registro do modo como liam música os antigos mestres da arte. Girolamo Diruta, no seu extenso tratado sobre a maneira correta de tocar órgão $e$ instrumentos de teclado $(1593,1609)$, dedica um livro inteiro da segunda parte do Il Transilvano ao ensino da arte de entabular. Para o autor, todo organista deveria dividir corretamente as linhas vocais ou instrumentais entre as duas mãos (pautas) na tablatura e ornamentá-las, transcrevendo, desse modo, uma partitura orquestral ou vocal para o teclado. Também, sob o mesmo princípio, estariam inclusos neste rol, os livro-parte que, durante o Renascimento registravam separadamente as diferentes linhas de uma obra polifônica executadas pelos instrumentos melódicos. Como atesta TAMMINGA (2010), faria 
parte dessa prática, a conversão e adaptação dos diferentes tactus das linhas de uma composição publicada em livros-parte em uma só battuta comum a todas as vozes. Para esse pesquisador, corroboram com esse entendimento as diversas publicações de tablaturas por autores que também deram luz a livros-parte das mesmas obras e, na redução ao teclado, converteram os ritmos particulares das diferentes prolações a outros mais coerentes com a uniformização do tactus.

\section{Referências bibliográficas}

ARISTÓTELES. Ars Poética. Edición Trilingüe por Valentín García Yebra. Madrid: Editorial Gredos, 1974.

. De Anima. Tradução de Maria Cecília Gomes dos Reis. São Paulo: Ed. 34, 2006.

. Política. Tradução de Nestor Chaves. Bauru: Edipro, 2009.

__ Retórica. Tradução de Paulo Farmhouse Alberto, Manuel Alexandre Junior e Abel Do Nascimento Pena. Lisboa: Martins Fontes, 2012.

ARTUSI, Giovanni Maria. L'arte del Contraponto - facsímile - Veneza, 1586. Bologna: Forni Editore, 1980.

. L'Artusi overo delle imperfettioni della moderna musica. Facsímile - Veneza, 1600. Bologna: Forni Editore, s/d.

BERMUDO, Juan. Declaracion de instrumentos musicales. Fac-símile Valladolid, 1555. Maxtor Editorial, 2009.

BOECIO. Sobre el fundamento de la música. Madrid: Gredos, 2009.

CASTIGLIONE, Baldassare. O Cortesão. Trad. Carlos N. M. Louzada. São Paulo: Martins Fontes, 1997.

DIRUTA, Girolamo. Il transilvano dialogo sopra il vero modo di sonar organi, et istromenti da pena - Fac-símile -Veneza, 1593 e 1609. Bologna: Forni Editore, 1960.

EXÍMENO, Antonio. Del origen y reglas de la musica, con la historia de su progresso, decadência y restauracion. Fac-símile - Madrid, 1774. Maxtor Editorial, 2010. 
FERNANDEZ, António. Arte de Musica de Canto Dorgam e Canto Cham \& Proporçoees de Musica divididas harmonicamente. Lisboa: Pedro Craesbeeck, 1626.

FOLIANI, Ludovico. Musica Theorica - facsimile - Veneza, 1529. Bologna: Forni Editore, s/d.

FRESCOBALDI, Girolamo. Fiori Musicali. Fac-símile - Veneza, 1635. Bologna: Forni Editore, 2010.

FURLAN, Mauri. A tradução retórica do Renascimento. In: FURLAN, Mauri (org.). Clássicos da Teoria da tradução. Volume 4. Florianópolis: UFSC/NUPLITT, 2006.

PÉCORA, Alcir. Apresentação. In: ACCETTO, Torquato. Da Dissimulação Honesta. São Paulo: Martins Fontes. 2001a.

. Máquina de Gêneros. São Paulo: Edusp, 2001b.

PICCOLOMINI. Alessandro. De la instituzione di tutta la vita de l'omo nato nobile, e in città libera. Venezia: Hyeronimus Scotum, 1542.

TAMMINGA, Liuwe. Prefazione. In: Musica Nova. Venezia 1540 Ricercari. Bolonha: Il Levante libreria editrice, 2010.

ZARLINO, Gioseffo. Le istitutione harmoniche. Facsimile - Veneza, 1558. Bologna: Forni Editore, 2008. 